\title{
Tiempo e historia en De cuando en cuando Saturnina
}

Paola Mancosu

Università di Cagliari

\begin{abstract}
This article is a reflection on the notions of 'time', 'history' and 'past' arising from an analysis of the science fiction novel De cuando en cuando SaturninaSaturnina from Time to Time- Una historia oral del futuro (2004) written by Alison Spedding (Belper, Inglaterra, 1962). The article shows how the novel disputes historical narrative and temporal linearity, advances a sharp social criticism of contemporary Bolivia and, above all, deconstructs hierarchies of power in the intersection of race, class and gender as historical constructions that legitimize social inequalities. Additionally, the article explores narrative mechanisms through which ideas of oral "counter-history" and Aymara temporal "concentricity" are reflected in the novel at structural and thematic levels.
\end{abstract}

\section{Keywords}

Aymara temporality, History; oral counter-history, past, science fiction, time 


\section{Resumen}

Este artículo surge de una reflexión sobre las nociones de "tiempo", "historia" y "pasado" a partir de un análisis de la novela de ciencia ficción De cuando en cuando Saturnina -Saturnina from Time to Time-Una historia oral del futuro (2004), escrita por Alison Spedding (Belper, Inglaterra, 1962). En particular, el artículo muestra cómo la novela cuestiona nociones de narrativa histórica y linealidad temporal, ofrece una aguda crítica social de la Bolivia contemporánea $\mathrm{y}$, sobre todo, deconstruye jerarquías de poder en sus interseccionalidades con categorías de raza, clase y género, como construcciones históricas que legitiman desigualdades sociales. El artículo busca también explorar los mecanismos narrativos mediante los cuales las nociones de "contra-historia" oral y "concentricidad" aymara temporal se reflejan en la novela, tanto a nivel estructural como temático.

\section{Palabras claves}

Ciencia ficción, contra-historia oral, historia, pasado, temporalidad aymara, tiempo

\section{Introducción}

Este artículo surge de una reflexión sobre las nociones de historia y de pasado a partir del análisis de la novela de ciencia ficción De cuando en cuando Saturnina -Saturnina from time to time-Una historia oral del futuro, publicada en La Paz en 2004, por la escritora y antropóloga Alison Spedding (Belper, Inglaterra, 1962) que, desde los años ochenta vive, escribe y conduce sus investigaciones etnográficas en los Andes bolivianos. Para analizar los conceptos de historia y de pasado en la novela, se ha recurrido a artículos antropológicos escritos por la autora y, en particular, a un texto de 2003, titulado "Quemar el archivo: un ensayo en contra de la historia". La conexión entre este ensayo y la novela no es casual, ya que no sólo se debe a la problematización común de conceptos como tiempo, historia y pasado, sino también a las referencias directas que la escritora hace, en su estudio "en contra de la historia", a De cuando en cuando Saturnina. A partir de un análisis de las interrelaciones entre los dos textos, se mostrará cómo la novela no se limita a cuestionar el relato histórico y la linealidad del narrar temporal occidental, sino que avanza una aguda crítica social de la Bolivia actual. 
Finalmente, este artículo se propone explorar los mecanismos narrativos mediante los cuales las ideas de "contra-historia" oral y de "concentricidad" temporal (Spedding, "Espacio, tiempo y lenguaje en los Yungas" 270), se reflejan en la novela tanto a nivel estructural como temático.

\section{Historia y ciencia ficción}

"Quemar el archivo: un ensayo en contra de la historia" (2003) es el título del artículo que Alison Spedding publica un año antes de De cuando en cuando Saturnina (2004). La relación entre estos dos textos, escritos en el mismo periodo, es profunda. Ambos reflexionan sobre la noción de historia, aunque desde perspectivas y géneros diferentes. En "Quemar el archivo", Spedding hace referencias explícitas a su novela de ciencia ficción, todavía inédita en ese entonces. Al introducir la última parte de su ensayo, titulada precisamente "La ciencia ficción como ausencia de la historia", anota que

[...] lo siguiente (incluyendo el Apéndice) procede de una novela de ciencia ficción inédita, sobre el futuro de lo que en ese entonces será la ex-Bolivia (como la llamarán en el exterior), o la Zona Liberada Qullasuyu Marka, como la llamarán sus propios habitantes. ("Quemar el archivo" 389)

Los últimos dos apartados del ensayo, en efecto, son extractos de la novela de ciencia ficción. Más exactamente, de un fragmento del capítulo "Mito e historia de Qullasuyu" (De cuando en cuando Saturnina 47-52) y del Apéndice final, titulado "Sobre la 'historia' de la Zona Liberada" (307-320). Al cotejar estas partes con sus correspondientes presentes en la edición de 2004 de la novela, se puede notar que se trata básicamente de los mismos textos. Hay que señalar, sin embargo, la incorporación de leves cambios a nivel léxico o inversiones con respecto a algún apartado. ${ }^{1}$ La inserción de estas secciones, como se verá más adelante, responde a la función ejemplificativa de mostrar la capacidad de la ciencia ficción para desestabilizar la linealidad temporal del método historiográfico y, al mismo tiempo, cuestionar la unicidad

\footnotetext{
1 Por ejemplo, los términos "incorporación", "reunir" y "principal" que aparecen en "Quemar el archivo" (391-392), son substituidos por "inclusión", "reclutar" y "protagónico" en De cuando en cuando Saturnina (307-308).
} 
de la historia. Resulta, por tanto, imprescindible analizar los nexos, sugeridos por la misma escritora, entre el ensayo y la novela de ciencia ficción.

En "Quemar el archivo", Spedding reflexiona sobre la concepción de historia considerada por cierta tradición historiográfica europea como una concatenación de eventos que del pasado van hacia el presente. Una visión lineal del tiempo que se ha impuesto como universal por el etnocentrismo de interpretar el pasado "según las reglas del discurrir occidental" (Ventura 54). Dicha tradición de pensamiento ha planteado, en base a estos principios, la distinción entre sociedades "históricas" y sociedades "ahistóricas". Distinción que, de acuerdo con los paradigmas teóricos vigentes en el período de enunciación, ha impuesto jerarquías entre sociedades "modernas" y "primitivas" ("Quemar el archivo" 367). Los archivos escritos, en este sentido, han representado el criterio discriminante de invisibilizar a la "gente sin historia", es decir, "las diversas historias activas de acosadas minorías" (Wolf 10). Como afirma Spedding, "la Historia es [...] escritura" ("Quemar el archivo" 374). Las sociedades ágrafas, de acuerdo con esta perspectiva, no tendrían historia, sino formas de elaboración de su pasado consideradas más bien como "mitos" o "supersticiones". Spedding, partiendo del presupuesto de que "toda sociedad posee una historia en el sentido de haber transitado por el tiempo" (368), problematiza el hecho de que se tome la escritura como criterio para establecer la historicidad (o ahistoricidad) de una sociedad determinada (367368). A pesar de que las representaciones del pasado sean múltiples, la Historia es una, en el sentido de que sólo una de ellas -normalmente la de los dominadores- es la que se convierte en hegemónica. Si por una parte existe una larga tradición en los estudios históricos dirigida a rescatar la memoria de las clases subalternas, por otra parte, observa Spedding, no se ha problematizado lo suficiente la forma en sí del relato histórico (368). Por tanto, la autora se pregunta si la Historia "que ha servido tan bien a la dominación podrá realmente convertirse en un instrumento de liberación", o si se tendría que acudir a otro concepto de historia (369). Lo que tendría que entrar en discusión, sugiere Spedding, no es sólo la visión única de la historia, sino también los métodos y valores con que opera la forma canónica de la historiografía occidental, que ordena los acontecimientos a través de un relato cronológico lineal.

La Historia selecciona, codifica y categoriza la memoria social y colectiva de acuerdo con criterios de "verdad" $y$ "falsedad". Las convenciones propias 
del método historiográfico determinan cuáles fuentes son fiables y cuáles no, cuáles datos son admisibles y cuáles no. Asimismo, el criterio de selección depende de un sinnúmero de variables que son, al mismo tiempo, subjetivas, sociales, metodológicas y, sobre todo, ideológicas y políticas (379). La Historia, por tanto, no debería considerarse como una realidad objetiva, sino como el resultado de una sistematización de relatos del pasado que responde a precisas exigencias del presente. A este propósito, la autora lanza una comparación provocativa entre la historia y la ciencia ficción cuando observa que:

[...] en el mismo estilo en que el/la escritor/a de ciencia ficción proyecta su ambiente contemporáneo hacia un 'futuro', el/la historiador/a proyecta el suyo hacia un 'pasado'. Es por este motivo que cada generación siente la necesidad de escribir nuevas Historias de la antigüedad clásica o del Incario, incluso cuando no han aparecido nuevas fuentes significativas, porque las proyecciones de una generación atrás ya no responden a las preocupaciones de hoy. (379)

La escritora define la ciencia ficción como "un género literario popular que ha cobrado vida en el curso del siglo XX" y que consiste, por lo general, en relatos "sobre 'el futuro'" (376). Al trazar un breve recorrido del género, la escritora propone que dicha literatura es una manera de indagar el presente. Una metáfora, para decirlo con Ursula K. Le Guin, "en infinita expansión exactamente adecuada para nuestro universo en expansión, un espejo roto, roto en innumerables fragmentos cada uno de los cuales es capaz de reflejar por un instante el ojo y la nariz izquierda del lector" (en López Pellisa 181). Una caja de herramientas en la que "sátira, extrapolación, predicción, absurdo, exageración, advertencia, mensaje, denuncia” (181) se convierten en estrategias literarias para describir las inquietudes de la sociedad actual (Molina-Gavilán 41-42). Con respecto a obras como Un mundo feliz (1932) de Aldous Huxley o 1984 de George Orwell (1949), Spedding recuerda que dichos autores recurrieron a la ciencia ficción en cuanto género más flexible que el ensayo o la novela canónica, para expresar su crítica socio-política y representar visiones utópicas o distópicas de su mundo contemporáneo. Incluso cuando esta intención no representa la finalidad principal de las obras de ciencia ficción, éstas acaban siendo "proyecciones" de la realidad social de sus autores. ("Quemar el archivo" 377)

Además, como subraya López Pellisa, "la ciencia ficción a menudo se ha convertido en una excelente metáfora de nuestra relación con el Otro". La narración de encuentros y desencuentros, así como la representación de 
conquistas espaciales funciona, a menudo, como "alegoría colonialista" o "alegoría de la inmigración" (193). En cuanto proyecciones implícitas o explícitas de la actualidad, los autores de ciencia ficción transponen en sus obras valores que son propios de su realidad contemporánea. Por esta razón, la descripción de la otredad ha padecido la influencia de prejuicios etnocéntricos y raciales. Sin embargo, según el análisis de Spedding, en la literatura de ciencia ficción encuentra cabida la representación de una realidad social cada vez más multicultural, donde el protagonista ya no es 'el blanco', mientras que su civilización y tecnología ya no constituyen lo más avanzado ("Quemar el archivo" 377). ${ }^{2}$ Esta inversión de tendencia podría ponerse en relación con cambios de mayor alcance. No es casual, afirma Spedding, que las mismas evoluciones "hayan aparecido en la Historia", más orientada, desde algunas décadas atrás, a poner al descubierto la voz de las y los subalternos y a "complejizar los esquemas analíticos" (377). A la vez, en la ciencia ficción irrumpen protagonistas femeninas y "el nuevo héroe tecnológico es el hacker, el empírico marginal que viaja por los intersticios de la Web". (377)

Muchos de los rasgos que se acaban de mencionar confluyen en De cuando en cuando Saturnina. La protagonista, Saturnina Mamani Guarache, conocida también como "La Satuka" desplaza enérgicamente la figura del héroe masculino blanco y del inventor, siendo una mujer indígena aymara, originaria de los Yungas, ${ }^{3}$ ciberterrorista y viajera espacial, famosa por ser "una de las navegadoras más calificadas del Sistema Solar en temas de inteligencia artificial". (De cuando en cuando Saturnina 178)

\footnotetext{
2 Hay que señalar, por ejemplo, el cuento El primer peruano en el espacio (2013) de Daniel Salvo, donde se reflexiona, a través del tema del viaje y de la colonización, sobre los encuentros con el otro y la complejidad de las clasificaciones sociales. Después de que los 'blancos' extraterrestres han invadido y conquistado la tierra, Anatolio Pomahuanca es el primer indígena-terrestre-peruano astronauta en realizar un viaje espacial. Si en la retórica del discurso colonial el otro siempre ha sido el indígena, representado como primitivo, bárbaro, ubicado en los límites de lo humano, en el relato de Salvo el alienígena es el 'blanco' que, en su expansión colonizadora, revela su monstruosidad (Mancosu, "Alteridad, viajes y conquistas" 5-6). Como afirma López Pellisa, "este relato nos recuerda inevitablemente la novela de Adolfo Bioy Casares De un mundo a otro (1999), donde se narra la historia del primer astronauta argentino en el espacio" (193). Podría también decirse que el relato de Salvo recuerda inevitablemente a la navegadora espacial Saturnina Mamani Guarache.

${ }^{3}$ Región boliviana situada al noreste de La Paz.
} 
De cuando en cuando Saturnina es un ejemplo de cómo la ciencia ficción puede reflexionar, de forma crítica e irónica, sobre la contemporaneidad, mediante una mirada distópica desde el futuro. Distópica porque el planeta -y sus periferias trans-globales- están lejos de haber solucionado problemas como el racismo, las discriminaciones de clase y de género, el libre tránsito de las fronteras o la violencia institucionalizada. La escritora avanza la crítica hacia un sistema globalizado interplanetario siempre más contradictorio, donde se exacerba "la radicalización de políticas migratorias destinadas a vigilar los movimientos poblacionales e impedir traslados masivos a centros económicos de prestigio" (Alfaro 347-348). Piénsese, por ejemplo, en la resolución de las Naciones Unidas para asignar el planeta Marte al "Pueblo Negro Panafricanista [...] en compensación por la esclavitud y lo que habían hecho a África con el colonialismo" (De cuando en cuando Saturnina 9). Los viajes espaciales de Satuka para acompañar a los "colonistas" a su nuevo planeta, son amenazados por los continuos ataques de los Fóbicos, "unos blancos racistas del sur de los Estados Jodidos, que en doscientos años no han podido olvidar que perdieron la guerra sobre la esclavitud" y que pretenden despojar a los afrodescendientes de Marte. (9)

Los avances tecnológicos relatados como previsibles, en cuanto resultado del progreso científico, son elementos que contribuyen a situar la novela dentro de las coordenadas del género (Capanna 15). A través de la andinización de la ciencia ficción, la ex-Bolivia y los Andes se proyectan en un futuro no tan alejado, pero lo suficientemente distante para ofrecer al lector una mirada objetiva que le permita reflexionar sobre el presente. La acción narrativa se sitúa en un arco temporal que va retrocediendo mediante una perspectiva que podría definirse como "(retro)futurista” (Gutiérrez León 2015, 152), desde el 2086 hasta el 2022, año de la insurrección indianista boliviana. La revolución determinó el fin del Q'ara timpu, es decir, de la época de los q'aras, ${ }^{4}$ la deconstrucción del Estado nación boliviano y la constitución del Qullasuyu Marka (o la Zona Liberada), basada en la reorganización de unidades comunitarias prehispánicas como los ayllus, en la eliminación de los medios de

\footnotetext{
${ }^{4}$ Como explica Spedding en el glosario final que acompaña la novela, el término q'ara alude a una "Persona no-campesina, no-india, de la clase media" (De cuando en cuando Saturnina 332).
} 
comunicación y en la sustitución de las leyes escritas por los quipus. ${ }^{5}$

La proclamación de un sistema económico autárquico determinó el cierre de las fronteras de la Zona Liberada "tanto por parte de los rebeldes como por parte de los Estados vecinos" (De cuando en cuando Saturnina v), a la vez que su expulsión del mercado neoliberal por parte de los "Estados Joddos". (15)

Como se lee en el texto que sirve de "prólogo" ("Desde los Andes a los asteroides. Voces de la revolución desconocida"), las únicas personas autorizadas a viajar fuera de las fronteras del Qullasuyu Marka "son los miembros del Sindicato", es decir de la "Space Engineering and Applied Astronomy Corporation 'Qullasuyu' plc", organización "de profesionales en ingeniería de programas y navegación espacial procedentes del Qullasuyu reconocida mundialmente por la alta calidad de sus servicios" (v). Su navegadora espacial más conocida es Saturnina Mamani Guarache, activista aymara del comando anarco-feminista Flora Tristán, grupo subversivo que, entre sus objetivos principales, tiene el de destruir cualquier forma de dominación "imperialista" y "patriarcal”. (101-102)

No obstante los intentos aislacionistas y las reconfiguraciones socioeconómicas y culturales inspiradas en organizaciones pre-coloniales, la élite masculina de los amawt'as ${ }^{6}$ sigue manteniendo el control sobre cualquier esfera política y social. Lejos de idealizar sistemas utópicos andinos, la escritora recurre al tiempo futuro de la ciencia ficción para reflexionar críticamente sobre cómo, pese a las luchas descolonizadoras, las jerarquías de poder, en su intersección entre raza, clase y género (Stolcke 2000, 42)

5 "Cordel del cual penden muchos otros cordelitos, con nudos que señalan números u otros datos allí registrados; modo prehispánico de llevar contabilidad y registrar otros datos" (De cuando en cuando Saturnina 332).

${ }^{6}$ El texto aclara que, en lengua aymara, "amawt'a: sabio, adivino, mago, curandero andino" (321).

7 Con respecto a la especificidad del contexto americano, Stolcke afirma que "la homología entre las relaciones entre sexo y género, y raza y etnicidad, sí que se da y que además existe un vínculo ideológico-político entre ambas relaciones. Diferencias de sexo no menos que diferencias de raza son construidas ideológicamente como 'hechos' biológicos significativos en la sociedad de clase, naturalizando y reproduciendo así las desigualdades de clase. Es decir, se construyen y legitiman las desigualdades sociales y de género atribuyéndolas a los supuestos 'hechos biológicos' de las diferencias de raza y sexo" (Stolcke 2000, 42). También véase, sobre la noción de "interseccionalidad", los trabajos de Belkhir y McNair Barnett; Harris y Bartlow; y Ngan-Ling Chow, Texler Segal y Tan Lin citados en la bibliografía. 
bajo formas camaleónicas, subyugando la Historia a sus propios intereses e ideologías. Descolonizar, como afirma Spedding, no significa invertir los términos jerárquicos, sino emprender, como en efecto muestra la novela, "la búsqueda de esquemas de pensamiento que efectivamente desentronicen el proceso colonial y las categorías resultantes de ello de su posición central" ("Descolonización" 104). De acuerdo con Burdette, De cuando en cuando Saturnina representa "una forma alternativa de construir la historia basada en la oralidad y, por lo tanto, necesariamente despegada de cualquier comprensión lineal del tiempo-espacio". (Burdette 120)

\section{La estructura narrativa y la “concentricidad” temporal}

En la economía de la ficción de la novela, que consta de treinta y cuatro capítulos, cabe señalar la presencia de un texto que funciona a modo de prólogo y de un Manual para la usuaria, además de un apéndice en el que se profundizan los hechos históricos que siguieron a la revolución indianista del 2022, y de un glosario final. En el "prólogo", titulado "Desde los Andes a los Asteroides. Voces de la Revolución Desconocida", supuestamente escrito por una compiladora ficticia, se lee que "este libro consiste en una colección de recopilaciones orales, sobre acontecimientos ocurridos en Qullasuyu Marka (la Zona Liberada que abarca a la mayor parte de la ex-Bolivia y el antiguo departamento peruano de Puno" (De cuando en cuando Saturnina v). Además de las coordenadas espaciales, la compiladora delinea las directrices temporales de los acontecimientos relatados, "la mayoría de los cuales acaecidos entre 2070 y 2085" (v). Asimismo, destaca el carácter testimonial ${ }^{8}$

\footnotetext{
${ }^{8}$ En De cuando en cuando Saturnina (50) cabe señalar las referencias a Si me permiten hablar... Testimonio de Domitila. Una mujer de las minas de Bolivia (1977), texto particularmente representativo de la escritura testimonial de mujeres y paradigma, por lo que concierne al análisis histórico, de las luchas mineras en Bolivia. Este relato testimonial recoge la experiencia de resistencia y de lucha de Domitila Barrios de Chungara (Potosí 1937- Cochabamba 2012), líder boliviana de la clase obrera, única mujer que participó en la Tribuna del Año Internacional de la Mujer, organizada en 1975 por la Organización de las Naciones Unidas. La recopiladora, la educadora brasileña Moema Viezzer, se limita a transcribir y estructurar el testimonio de la "historia oral" de una mujer minera a partir de sus recuerdos y memorias.
} 
de lo relatado que, a pesar de tener el objetivo principal de narrar la "vida y milagros de Saturnina Mamani Guarache" (v), se constituye como una recopilación de diferentes conversaciones, "más que entrevistas propiamente dichas" (vii), realizadas con distintas mujeres. De este modo, anota la compiladora:

[...] hemos podido conocer a Ms Mamani Guarache, que solía trabajar junto con su compañera FORTUNATA ALVISURI, a ambas en el bar 'El Último y Nos Vamos' de Ceres Orbital. Ms Alvisuri se interesó en colaborar con nuestro proyecto y, como se verá, se convirtió en la informante principal. Después se incorporó Ms Mamani Guarache en persona, y se pudo reconstruir conversaciones entre ella y Ms Alvisuri y otras, como Imelda Mamani, hermana menor de Saturnina, Cleoje Mamani, la madre de ellas, y 'Feliciana', el nombre de guerra de una ex-combatiente del Comando Flora Tristán, refugiada en la Zona Liberada. También tuvimos la suerte de poder registrar un testimonio personal -en una sesión de ch'amakani- de ALCIRA MAMANI GUARACHE, abuela materna de Ms Mamani Guarache y Ch'aman Tayka, o Benemérita de la Patria, que murió en 2062. (vi)

Se especifica, además, que quien reúne los testimonios se limita a transcribirlos, sin nunca intervenir ni comparecer entre las voces que narran. Podría tratarse, entonces, de una investigadora de ciencias sociales o de una historiadora, como sugiere el empleo de los términos "informante principal" o "entrevistas", propios de técnicas de investigación etnográficas o de una metodología más propia de la historia oral. ${ }^{9}$ El proyecto al que se hace referencia consiste en reconstruir la historia del Qullasuyu Marka. La finalidad es la de ofrecer una visión interna de los hechos desde una perspectiva femenina que sea capaz de superar las representaciones "oficiales" del Qullasuyu Marka, descrito y demonizado por los Estados Jodidos y por sus

\footnotetext{
${ }^{9}$ Cabe señalar el trabajo del Taller de Historia Oral Andina (THOA), fundado en 1983 en Bolivia, que precisamente a través de la metodología de la historia oral, se planteó la recuperación del pasado histórico y la memoria social de los movimientos indígenas en contra del discurso historiográfico tradicional. Se trataba de elaborar una historia capaz de desestructurar las relaciones de poder que, después de la formación de los Estados-nación, continuaron recreándose mediante formas de "colonialismo interno". Este concepto, propuesto por Pablo González Casanova (1969) y luego reelaborado por Silvia Rivera Cusicanqui, fundadora del THOA, alude al "conjunto de contradicciones diacrónicas de diversa profundidad, que emergen a la superficie de la contemporaneidad, y cruzan, por tanto, las esferas coetáneas de los modos de producción, los sistemas políticos estatales y las ideologías ancladas en la homogeneidad cultural" (Rivera Cusicanqui 37).
} 
aliados como "arcaicista, racista y sanguinario" (vi). El resultado, explica la recopiladora, fue el de abrir esa "Cortina de Hierro en los Andes" que había permanecido "herméticamente cerrada al resto del mundo" desde la revolución indianista. De este modo, la novela adquiere una estructura polifónica en cuanto yuxtaposición de relatos "realizados con diferentes personas en diferentes ocasiones", que en ningún momento "conforman un sólo relato lineal" (vii). La oralidad es recreada mediante un lenguaje híbrido, mezcla de aymara, español andino y spanglish, "además de los otros idiomas corrientes en el espacio, como Trade Japanese (viii). Como observa Raquel Alfaro:

la intervención de la esfera del spanglish por parte del aymara y castellano andino [muestra] la repetición (invertida) del procedimiento de dislocación llevado a cabo con éxito en el caso del castellano, a la par de sugerir que los procesos de resistencia que acompañan a esta intervención lingüística siguen obrando y consiguiendo resultados a pesar del cambio formal del escenario político: de uno mundial a uno galáctico". (346-347)

La recopiladora ficticia logra dar voz al discurso femenino en torno a los procesos de cambio radical y de descolonización de la ex-Bolivia, con respecto a un periodo que va desde 2022 hasta 2086. Discurso que ha sido silenciado por las versiones hegemónicas oficiales y por los registros escritos autorizados. El texto ficcional se convierte, entonces, en una herramienta de denuncia de la exclusión de las mujeres de la Historia y de su ausencia del discurso político en la Bolivia actual y real (Arnold y Spedding 15). A este propósito, Julieta Paredes, teórica del movimiento feminista boliviano Mujeres Creando Comunidad, ${ }^{10}$ reivindica el papel femenino en la Historia:

Lo que no fue tomado en cuenta fueron los nombres de esas mujeres, ellas ya no figuran en los documentos, libros o archivos, y tampoco sus aportes figuran como ideas o aportes de mujeres [...]. Los libros, documentos y archivos han sido hechos para visibilizar las formas de ver de los grupos hegemónicos. $(2006,63)$

${ }_{10}$ Mujeres Creando es un movimiento social feminista boliviano que, desde los años noventa, es protagonista de un cambio social y político dirigido a desestructurar los modelos hegemónicos patriarcales y coloniales, y superar las desigualdades sociales, étnicas, culturales y políticas. En 2002 , se produce una fractura en el movimiento y nace la propuesta de un feminismo comunitario elaborado por Mujeres Creando Comunidad. 
Spedding, en línea con Paredes, otorga voz, nombres, agencia política, social e histórica a las mujeres y a sus visiones anti-hegemónicas. No sólo destaca la importancia de rescatar la oralidad, sino que consigue desafiar los esquemas y la naturaleza teleológica del relato historiográfico tradicional. En su ensayo "Quemar el archivo" ya planteaba la dificultad de reconstruir la simultaneidad de diferentes historias orales del pasado, cuando anotaba lo siguiente:

La 'historia oral' generalmente consiste en la recopilación de recuerdos personales, de la vida de uno o de lo que se ha escuchado de otros. Esto no es muy problemático cuando se limita al 'testimonio', el relato de una persona. Sin embargo, surgen varias dificultades cuando se intenta utilizar material procedente de varias personas para componer un relato histórico de cierto acontecimiento o serie de acontecimientos. ("Quemar el archivo" 370-371)

Para reproducir el flujo inconexo de las conversaciones y cuestionar, de este modo, la narración histórica convencional, en De cuando en cuando Saturnina, Spedding recurre a una estructura narrativa fragmentada. En el Manual para la usuaria, una suerte de introducción que constituye parte integrante de la novela, se sugiere la posibilidad de seguir diferentes órdenes de lectura. Gráficamente, el índice de los capítulos está acompañado por letras $(S, Q, T$ y $P)$ que señalan las posibles secuencias narrativas. La letra $S$ responde al orden en el que está impresa la novela. Este orden, supuestamente "impuesto por los editores" ficticios (vii), refleja una estructura concéntrica, en la que la contemporaneidad de las conversaciones entre las protagonistas sobre todo entre Fortunata y Satuka- se entreteje con el pasado de sus recuerdos y memorias. Dicha estructura implica, como se señala en el Manual, "un juego de rayuela" (viii) según el cual los hechos pasados "aparecen como encajados dentro de narraciones sobre hechos "contemporáneos'" (viii). Otras posibles secuencias se pueden reconstruir a partir de la letra $T$, relativa a la cronología de los hechos más importantes desde el momento en que Fortunata conoce a Satuka, y de la letra $P$, que indica los eventos del pasado. Además, la secuencia $\mathrm{Q}$ ofrece la posibilidad de deshilvanar la sucesión narrativa y cronológica, siguiendo el punto de vista de los personajes que relatan la historia. Este orden abierto de lectura deja la posibilidad a la "usuaria" de reconstruir su propia sucesión narrativa. Se trata, entonces, de una estructura que pone en discusión los métodos y las formas canónicas de la historiografía occidental y de su proceder lineal. En un artículo escrito en 1996 sobre el tiempo y el espacio en los Yungas bolivianos, Spedding observa que en los 
testimonios uno no cuenta sobre su vida "empezando con sus padres y/o su nacimiento y procediendo en forma ordenada hasta el día de hoy, sino que presenta ciertos eventos en tanto que el contexto actual les evoca, y el orden de la narración asemeja más a Rayuela de Julio Cortázar que a Ocaso y caída del Imperio Romano de Edward Gibbon". ("Espacio, tiempo y lenguaje en los Yungas" 276)

La referencia intertextual a la estructura narrativa de la obra cortazariana, presente tanto en el artículo de 1996 como en la novela de 2004, tiene la función de subrayar la necesidad de desprenderse del orden cronológico. Un orden que no sigue una linealidad que del punto A llega al punto B. Los recuerdos son contados, más bien, saltando de un momento a otro de la vida personal de las narradoras, entrecruzando acontecimientos y experiencias de forma caótica y, de todas maneras, no teleológica. El tiempo se comprime o dilata, se maneja y estira en relación con la importancia que la narradora atribuye a un evento $y$, por supuesto, se omiten particulares o secuencias que no son determinantes para la economía del relato que se quiere narrar.

Por esta razón, en De cuando en cuando Saturnina el tiempo de lo narrado fluye de forma caótica, alternando relatos en primera persona y diálogos directos. Por ejemplo, en el capítulo S1, Fortuna relata a la recopiladora las circunstancias en que conoció a Satuka, mientras que todo el capítulo S11 se estructura como un largo diálogo directo entre las dos narradoras. Esta estrategia narrativa consigue transmitir la inmediatez de lo contado y establecer nexos entre lo vivido y lo narrado. El entramado narrativo se construye a través de "un hilo temporal extremadamente fluido", como diría Barrenechea comentando la estructura de Rayuela (218). En De cuando en cuando Saturnina, además, el tiempo de las narradoras no coincide con el tiempo de lo narrado. Como destaca la compiladora: "siempre se relata después de los hechos relatados, pero la relación entre el momento de la conversación y el o los momentos de los hechos relatados es bastante variable" (De cuando en cuando Saturnina viii). La autora logra alternar planos temporales diferentes, yuxtaponiendo el presente, el pasado y el futuro. El tiempo en que la recopiladora graba las entrevistas, alrededor de 2086, se distingue del tiempo de lo narrado de las entrevistadas, que retrocede hasta el 2022, gracias a la memoria de diferentes protagonistas, incluso difuntas. En definitiva, la parcelación de los relatos consigue reproducir la pluralidad y simultaneidad de las voces en juego. 
Para entender el funcionamiento estructural del texto puede ser útil acudir a un artículo escrito por la autora sobre las nociones de tiempo y espacio aymara. En la novela, en efecto, parecen reflejarse algunas particularidades de la visión temporal propia de la lengua aymara, que Spedding examina en su análisis de las categorías gramaticales relativas al tiempo. ${ }^{11}$ En particular, es significativa la estructura verbal de los "tiempos de conocimiento personal" (es decir, el tiempo simple, el futuro y el remoto cercano), denominados de este modo porque tienen en común el hecho de expresar un conocimiento subjetivo de los acontecimientos. Conocimiento que puede ser directo o indirecto, es decir, "lo que uno mismo ha visto y recuerda" o "lo que recuerdan [o han visto] otras personas" ("Espacio, tiempo y lenguaje en los Yungas" 270). El tiempo simple expresa una acción, presente o pasada, "lo que puede ser visto o lo que ha sido visto por el hablante" (Hardmann, Vásquez y Yapita 144). El tiempo futuro es usado para hablar sobre eventos que todavía no han acontecido, pero que dependen siempre de datos personales conocidos por el locutor. En fin, el remoto cercano tiene, entre sus varios usos, el referirse a eventos pasados de los que "el hablante tiene recuerdo personal" (146). Por tanto, el punto de vista de quien habla es siempre el que establece el grado de verosimilitud de los hechos relatados. En este sentido, explica Spedding, "no estamos frente a una historia 'lineal' sino una especie de historia 'concéntrica', centrada en el individuo que habla y que extiende a su alrededor en círculos irregulares según las circunstancias contingentes de su propia experiencia y los valores que le otorga" ("Espacio, tiempo y lenguaje en los Yungas" 270). Esta visión del tiempo se refleja en la estructura de De cuando en cuando Saturnina, donde el conocimiento personal de las narradoras es central para reconstruir la "memoria colectiva" de unas historias que se relatan de modo no lineal, ampliándose en círculos concéntricos e irregulares. La singularidad de la estructura narrativa de la novela, de acuerdo con Burdette, "no sólo responde a una tentativa de construir una 'historia oral escrita' que corresponda a nociones aymaras del tiempo-espacio, sino también a una subversión de la lógica estatista inherente al modelo historiográfico tradicional". (121)

Esta concepción del tiempo aymara, además, se reencuentra en las palabras de la abuela Alcira cuando explica que "no se puede decir 'destino histórico' en aymara. En la escuela nos decían nayrapachat qhipkama

\footnotetext{
11 Para un análisis de la concepción del tiempo aymara en De cuando en cuando Saturnina, véase Gutiérrez León $(2011,78)$ y Burdette (119).
} 
sarnaqawïsa [nuestra forma de vivir mirando desde el pasado hacia el futuro] al hablar de cómo se incorporó Puno" (De cuando en cuando Saturnina 87). Los términos aymara nayra y qhipa que se hallan en la frase reflejan una visión temporal que invierte la idea occidental del pasado y del futuro. En su etnografía sobre una comunidad aymara de los Andes bolivianos, Canessa destaca la importancia, en el pensamiento aymara, de la idea de un pasado que no es "remoto e inaccesible sino, al contrario, visible e inmanente", concepción que puede comprobarse en la lengua aymara. El término que se refiere al pasado, nayra, también significa "ojos", mientras que la palabra que designa el futuro, qhipa, también indica "atrás". "El futuro está entonces atrás, invisible e incognoscible, y el pasado delante, visible gracias al conocimiento personal, pero también a través de la comunicación con los antepasados" (Canessa 32. Traducción de la autora).

\section{La contra-historia}

En De cuando en cuando Saturnina, Spedding no sólo consigue desestabilizar la linealidad del relato histórico, sino también poner en discusión la distinción entre mito e historia. Distinción que valdría menos en las sociedades ágrafas al tratarse, afirma la autora, de "una invención occidental y mayormente moderna", según la cual la Historia representaría un 'avance' del mito, en cuanto 'expurgada' de los elementos irreales o inverosímiles, clasificados como mágicos o míticos" ("Quemar el archivo" 371, 373). El relato histórico, continúa Spedding, "debe ser verdadero y [...] esa verdad es única, es decir, hay una sola serie 'real' de acontecimientos para ser identificados y registrados". (371)

Por lo contrario, Spedding, con su novela, propone una "historia oral del futuro" donde lo irreal es parte de la realidad cotidiana "reconocible por el lector" (Roas 58). Piénsese, por ejemplo, en la figura de la abuela difunta, que representa "un ente dinámico, y su participación en la vida de su nieta (y en la trama del libro) no es menor que la de cualquier otro personaje secundario" (Gutiérrez León 2015, 162). La normalización de su presencia "plantea la coexistencia no problemática de lo real y de lo sobrenatural" (Roas 57). Saturnina, a pesar de que las mujeres en el Qullasuyu Marka no puedan ejercer la actividad de ch'amakani (chamán que convoca las almas de los difuntos), consigue robar la calavera de su abuela difunta al gremio de los amawt'as, para realizar la mesa ritual (apxata) y 'llamar' a su espíritu (De cuando en cuando 
Saturnina 24, 53). Ritual que en el texto funciona como mecanismo narrativo para naturalizar lo extraño. El cuestionamiento no problemático entre lo posible y lo imposible, definido por David Roas como uno de los rasgos característicos del realismo mágico, remite más bien, en el caso específico de la narración de Spedding, a una idea común dentro del complejo horizonte simbólico-cultural andino asociado a la muerte, según la cual los difuntos están presentes en la realidad cotidiana de los vivos, en una relación de intercambio. ${ }^{12}$ De este modo, la abuela regresa del mundo de los muertos para aconsejar a Saturnina en su lucha en contra del poder dominante.

Aunque el Qullasuyu Marka represente un cambio social significativo, la élite que sigue manteniendo el poder reproduce -bajo otros avatares- el mismo manejo de la Historia. El nacionalismo del Qullasuyu Marka fundamenta su pasado a través de momentos constitutivos e indispensables para recrear una historia oficial única, depurada de las ambigüedades inherentes a los procesos de cambio social. Un ejemplo paradigmático es el relato de la manifestación anual con que el Qullasuyu Marka conmemora el nacimiento de la Patria y la revolución indianista. Se trata del fragmento que Spedding injerta en su "ensayo en contra de la historia" ("Quemar el archivo" 380), ejemplificativo de cómo la Historia "otra" puede volverse "oficial". ${ }^{13}$ Significativamente, al relato histórico del mito fundacional del Qullasuyu Marka, se opone la narración de la abuela que, como subraya Satuka, cuenta los eventos "de otra forma" (De cuando en cuando Saturnina 52). La abuela Alcira, que ha participado y, por tanto, visto, y puede contar con un buen grado de confiabilidad esa historia, pone en tela de juicio la versión oficial del Qullasuyu Marka, dejando emerger toda la complejidad de la revolución, ausente en el relato de la nueva élite de los amawt'as. Al describir el periodo de convulsión política, Alcira recuerda que

lo que sí había era un caos... nada como lo que enseñan a Vds ahora en el Yachaywasi, yo mey admirado de cómo se confecciona la historia. Ahora

\footnotetext{
12 Según la visión aymara, así como en sociedades agrarias de otras áreas, el equilibrio cíclico vital dentro del espacio comunitario y su entorno se traduce simbólicamente con la idea según la cual los muertos intervienen directamente tanto en el ciclo agrícola como en el ciclo vital de las personas. Una visión según la cual la muerte se podría concebir como descanso (Fernández Juárez 2).

${ }^{13}$ Con la misma finalidad, en "Quemar el Archivo" la autora injerta el "Apéndice final" de De cuando en cuando Saturnina, donde se relata la situación caótica y contradictoria que caracteriza la época relativa a la revolución indianista de 2022.
} 
dicen que la historia que enseñaban antes era puras mentiras de $q^{\prime}$ aras pero ahora será mentiras de amawt'as, diría yo. (55)

El nacionalismo de los amawt'as elige fechas e imágenes simbólicas para cimentar su proyecto ideológico y teocrático andino. No obstante la superación del Estado-nación moderno, el Qullasuyu Marka continúa recreando -bajo formas diferentes- desigualdades sociales. En este sentido, como afirma Spedding en "Quemar el archivo", "los cambios revolucionarios tardan en llegar a toda la sociedad $y$, en varios casos, las élites establecidas eventualmente logran mantener su posición bajo otros nombres u otros puestos" ("Quemar el archivo" 379-380). El discurso oficial del Qullasuyu Marka reconstruye su origen a través de una representación mítica de la historia andina y de conceptos idealizados de la sociedad prehispánica, como por ejemplo la complementariedad de género, conocida a través del término chachawarmi, compuesto por las palabras "hombre" (chacha) y "mujer" (warmi). Según el relato de la abuela, durante la guerrilla de independencia, los revolucionarios de la Brigada Felipe Quispe hacían un uso instrumental de este concepto. A pesar de emplear la retórica de la igualdad teóricamente basada en la dualidad andina entre hombre y mujer, las tropas rebeldes reproducían, en la práctica, las jerarquías de género todavía vigentes en 2022. Alcira denuncia que, al mando de las brigadas y de los movimientos sociales, todos los p'iqi -palabra que en aymara significa "cabeza” y, por extensión, aquí se refiere a "jefe" - eran hombres. La novela, de este modo, llama la atención sobre el uso idealizado de las relaciones de género del sistema comunal rural andino en la Bolivia actual, en particular, por parte de instituciones estatales como el Viceministerio de la Mujer, o por organizaciones sindicales (Arnold y Spedding 160). En este sentido, siguiendo al grupo feminista Mujeres Creando Comunidad, no está por demás notar que en este binomio primero se menciona al hombre y después a la mujer (Paredes 2008, 29), ya que las relaciones entre los géneros están lejos de ser complementarias, igualitarias y armónicas en la realidad boliviana contemporánea. En la novela, la crítica sagaz hacia su uso demagógico se resume en las palabras de Satuka cuando afirma: "Nos cagamos en esas babeadas de chachawarmi, qué hay de la complementariedad si al fin los hombres siguen copando los puestos directivos". (De cuando en cuando Saturnina 101)

El Qullasuyu Marka, entonces, no se representa como un sistema idílico, exento de desigualdades y violencia. Pese a la superación del Estado-nación moderno, la sociedad del Qullasuyu Marka continúa recreando las jerarquías 
de poder en su interseccionalidad entre clase y género (Branca y Mancosu 256). De clase, porque hay una élite de amawt'as que impone "cierto control social institucionalizado" (De cuando en cuando Saturnina 125) sobre diferentes ámbitos de la vida a través de varios dispositivos, coercitivos o no, de género, porque los que todavía ejercen el poder son hombres, mientras que a las mujeres se les asigna cargos absolutamente menores. No se trata de un rescate nostálgico de estructuras pre-coloniales, sino de cuestionar una sociedad que, no obstante sus transformaciones radicales, sigue siendo, como afirma Fortunata, "todavía patriarcal" (239). Por esta razón, declara Satuka, "somos la revolución permanente", "el contra-poder". $(82,101)$

De cuando en cuando Saturnina reivindica una genealogía de pensamiento crítico femenino. En este sentido, el nombre del Comando subversivo es un claro homenaje a Flora Tristán (1803-1844), pensadora franco-peruana del siglo XIX considerada hoy día como una de las fundadoras del feminismo moderno. La Red de Capacitación Femenina "Clorinda Matto de Turner" -que luego vendrá a ser el Comando Flora Tristán- es así llamada en clara alusión a Clorinda Matto de Turner (1852-1909), una de las iniciadoras del género literario indigenista en el Perú. Asimismo, en una conversación entre Satuka y Fortunata, se nombra a Domitila Barrios de Chungara (19372012), líder en la lucha obrera y minera durante las dictaduras de Barrientos y Banzer en Bolivia. Se trata, entonces, de un rescate del discurso político femenino y de una crítica a la Historia que no "permite hablar" a una parte de la sociedad.

En contra de la folklorización y comercialización de la historia, las acciones terroristas de Satuka y del Comando Flora Tristán ponen en tela de juicio el uso instrumental del "pasado social" (Wallerstein 373) canibalizado por la retórica del Estado-nación y los intereses económicos de un sistema neoliberal que ha alcanzado dimensiones interplanetarias. El Comando destruye el templo inca de la Coricancha, en el Cusco, recién reconstruido por el Estado peruano con el propósito de vender una historia incaica, transfigurada y recortada, para el uso de los consumidores. Como explica Saturnina, de forma irónica, la reconstrucción del edificio incaico para el turismo masivo es "un verdadero tributo en acción a la profunda espiritualidad originaria, etcétera, etcétera" (De cuando en cuando Saturnina 197). Este acto subversivo está dirigido a denunciar, como diría Spedding, "Ios usos y abusos" de la Historia ("Quemar el archivo" 380). A raíz de este atentado Saturnina es encarcelada por la policía 
peruana. En la entrevista que algunos periodistas logran hacerle, explica las razones de sus ataques:

Periodista: “¿Vd es la jefa del Comando Flora Tristán?"

Satuka: "No tenemos jefas, somos anarquistas"

P: "¿Vds son dirigidos desde la ex-Bolivia?"

S: "Bolivia dejó de existir hace sesenta años. Yo soy de Qullasuyu Marka. Y no me ha mandado nadie, he venido por mi propia voluntad"

P: "¿Vd es la navegadora que destrozó Fobos?"

S: "También. Me cago en el racismo en todas partes"

P: “¿Cómo justifica Vd el venir a un país ajeno, masacrar a sus ciudadanos y destrozar sus monumentos históricos?"

S: "Lo hice en nombre de las limosneras que se sientan en las sombras desos edificios coloniales"

P: "iLa Coricancha no es un edificio colonial!"

S: "iSí lo es! Los incas eran unos imperialistas de mierda también"

P: "iNo hay limosneros en el Cusco!"

S: Eso es porque los han sacado a todos para que vengan Vds. Si vuelven dentro de seis meses allí van a estar, molestándole con sus aparatos aprobados por el Ministerio de Asuntos Campesinos para que puedas pagar la limosna con tarjeta de crédito". (De cuando en cuando Saturnina 209-210)

A una recreación idealizada de la historia andina, Spedding opone una visión iconoclasta de los símbolos del imperialismo y de las jerarquías de poder que han caracterizado tanto la sociedad colonial como la incaica, y que siguen recreándose en el futuro narrado por la novela. Jerarquías de poder que se denuncian en su interseccionalidad históricamente problematizada entre género, raza y clase, en distintos episodios del relato. Quizá el más representativo sea precisamente el momento en que Saturnina reivindica sus atentados en nombre de las limosneras indígenas sentadas "a las sombras" de los monumentales edificios "coloniales". Es decir, de aquellas mujeres triplemente subalternizadas: en cuanto mujeres, en cuanto mujeres indígenas, y en cuanto mujeres indígenas económicamente explotadas. (Stolcke 2004, 93)

\section{Conclusiones}

Como afirma Serge Gruzinski en su ya clásico estudio El pensamiento mestizo, "el tiempo de los vencedores no sólo no reemplaza automáticamente al de los vencidos, sino que también pueden coexistir durante siglos" (Gruzinski 58-59). Como es sabido, existen diferentes concepciones del tiempo y del espacio que, sobre todo en territorio americano, van superponiéndose a lo 
largo de las décadas. El desorden narrativo de la historia oral relatada en De cuando en cuando Saturnina es, en realidad, sólo aparente. La novela remite a una noción del tiempo aymara, a un pasado y a unas historias "concéntricas" que consiguen desprenderse de la linealidad temporal de la ontología occidental, romper las normas implícitas del relato histórico y desestructurar un concepto de Historia universal. La ciencia ficción, con su flexibilidad, ironía y parodia, sugiere otra forma de narrar el pasado y consigue ir más allá de las distinciones entre mito e historia, real e irreal, posible e imposible.

Como se ha mostrado, los nudos que entrelazan el estudio escrito por Spedding en 2003 y la novela De cuando en cuando Saturnina son múltiples. Ambos textos, en conclusión, apuntan a una reflexión sobre la noción de "historia" y sobre los métodos tradicionales de escribirla. La novela, de este modo, plantea la posibilidad de una contra-historia a través de su estructura narrativa no lineal, así como el rescate de un discurso femenino capaz de desjerarquizar las formas cambiantes del poder. A este propósito, el título del ensayo de 2003, "Quemar el archivo", resulta ser particularmente significativo, ya que sugiere la reflexión, explicada por Spedding, sobre la quema de los registros escritos como acto de reivindicación en las luchas sindicales y campesinas modernas de la Bolivia actual. Acto que representa, según la autora, "una clara percepción de la Historia oficial como herramienta de dominación". (Quemar el archivo 389)

En De cuando en cuando Saturnina la quema de los registros se traslada metafóricamente al futuro. Saturnina, hacker especialista o, mejor dicho, onlinecamayoq ${ }^{14}$ del Comando Flora Tristán, destruye el archivo de la Sección Genética del Ministerio de Asuntos Indígenas del Estado peruano "por ser la sección más facha" del Ministerio, rebautizado por la misma protagonista como "de Turismo y Folkloricultura" $(18,16)$. Institución que tiene el papel de establecer el porcentaje de sangre indígena de una persona (" $100 \%, 85 \%$, o $50 \%$ ") mediante el análisis de criterios como "nombres de los tatarabuelos, pruebas de cromosomas, color de la piel, análisis del pelo..." (18), para "certificar" quiénes pueden trabajar como "indígenas". Saturnina, bajo una identidad falsa, consigue infiltrarse como trabajadora de limpieza en las oficinas del Ministerio para realizar un ataque ciberterrorista que destruya los

\footnotetext{
${ }^{14} \mathrm{El}$ término une la palabra inglesa online (en línea) con la quechua camayoq (oficial inca encargado de cuidar algo) y hace referencia al quipucamayok, el que transmitía informaciones a través de los quipus.
} 
registros informáticos de la Sección. Una quema que irrumpe, simbólicamente, en las grietas del Web y del tiempo, y que pone en discusión los excesos del sistema capitalista, que han ido canibalizando lo étnico dentro de sus intereses de mercado, así como los "usos y abusos" de la cultura y de la Historia.

\section{Bibliografía citada}

ALFARO, Raquel. 2008-2010. Reseña de Alison Spedding. De cuando en cuando Saturnina (Saturnina from Time to Time): una historia oral del futuro. Bolivian Studies Journal 15-17. 346-349.

ARNOLD, Y. Denise y Alison Spedding. 2005. Mujeres en los Movimientos Sociales en Bolivia 2000-2003. La Paz: CIDEM/ILCA.

BARRENECHEA, Ana María. 1981. "La estructura de Rayuela de Julio Cortázar". Julio Cortázar. El escritor y la crítica. Pedro Lastra, ed. Madrid: Taurus. 207-224.

BARRIOS DE CHUNGARA, Domitila. 1977. "Si me permiten hablar..." Testimonio de Domitila, una mujer de las minas de Bolivia. Moema Viezzer, ed. México D. F.: Siglo XXI Editores.

BELKHIR, Jean Ait y Bernice McNair Barnett. 2001. "Race, Gender and Class Intersectionality". Race, Gender \& Class 8 (3): 157-174.

BRANCA, Domenico y Paola Mancosu. 2017. "De cuando en cuando Saturnina. Antropología y ciencia ficción". Confluenze. Rivista di Studi Iberoamericani" 9 (2): 239-263.

BURDETTE, Hanna A. 2011. "Futurismo arcaizante: descolonización y anarcofeminismo en De cuando en cuando Saturnina". Bolivian Studies Journal 18. 115-133.

CANESSA, Andrew. 2012. Intimate Indigeneities. Race, Sex, and History in the Small Spaces of Andean Life. Durham and London: Duke University Press.

CAPANNA, Pablo. 1966. El sentido de la ciencia-ficción. Buenos Aires: Editorial Columbia.

FERNÁNDEZ JUÁREZ, Gerardo. 2001. "Almas y difuntos: ritos mortuorios entre los aymara lacustres del Titicaca”. Chungara. Revista de Antropología Chilena 33 (2): 201-219.

GRUZINSKI, Serge. 2000. El pensamiento mestizo. Barcelona: Paidós.

GUTIÉRREZ LEÓN, Anabel. 2011. “Después del Pachakuti. Tiempo mitológico aymara y ciencia ficción". Mitologías Hoy. Revista de pensamiento, crítica y estudios literarios latinoamericanos 3. 75-84.

[http://revistes.uab.cat/mitologias/article/view/v3-gutierrez] página descargada el 2 de febrero, 2018. 
---. 2015. "De cuando en cuando Saturnina. Trilogía de una india rebelde de Alison Spedding. Mitologia y subversion en los Andes". Fragmentos de un nuevo pasado. Inventario de mitos prehispánicos en la literatura latinoamericana actual. Helena Usandizaga y Beatriz Ferrús, eds. Oxford: Peter Lang. 149-177.

HARDMAN, Martha J., Juana Vásquez y Juan de Dios Yapita, eds., 2001. Aymara. Compendio de estructura fonológica y gramatical. Segunda edición. La Paz: Instituto de Lengua y Cultura Aymara (ILCA).

HARRIS, Angelique y Susannah Bartlow. 2015. "Intersectionality: Race, Gender, Sexuality, and Class". Handbook of the Sociology of Sexualities. John DeLamater y Rebecca Plante, eds. New York: Springer International Publishing. 261-271.

LÓPEZ PELLISA, Teresa. 2015. "Incas y extraterrestres en la ciencia ficcion peruana contemporánea: José B. Adolph y Daniel Salvo". Fragmentos de un nuevo pasado. Inventario de mitos prehispánicos en la literatura latinoamericana actual. Helena Usandizaga y Beatriz Ferrús, eds. Oxford: Peter Lang. 181-204.

MANCOSU, Paola. 2017. "Alteridad, viajes y conquistas en la ciencia ficción peruana y boliviana". Medea. Rivista di Studi Interculturali 3 (1): 1-19.

MOLINA-GAVILÁN, Yolanda. 2002. Ciencia ficción en español: una mitología moderna ante el cambio. Latin American Studies 16. Lewiston: New York, Edwin Mellen Press.

NGAN-LING CHOW, Esther, Marcia Texler Segal y Lin Tan, eds. 2011. Analyzing Gender, Intersectionality, and Multiple Inequalities: Global, Transnational and Local Contexts. Advances in Gender Research 15. Bingley: Emerald Publishing.

PAREDES, Julieta. 2006. "Para que el sol vuelva a calentar". No pudieron con nosotras: El desafío del feminismo autónomo de Mujeres Creando. Elizabeth Monasterios Pérez, ed. La Paz: Plural Editores. 61-95.

---. 2008. Hilando Fino (Desde el feminismo comunitario). La Paz: CEDEC.

RIVERA CUSICANQUI, Silvia. 2010. Ch'ixinakax utxiwa. Una reflexión sobre prácticas y discursos descolonizadores. Buenos Aires: Tinta Limón Ediciones.

ROAS, David. 2011. Tras los límites de lo real. Una definición de lo fantástico. Madrid: Páginas de Espuma.

SPEDDING, Alison. 1996. "Espacio, tiempo y lenguaje en los Yungas". Las armas de la utopía. Marxismo: provocaciones heréticas. Álvaro García Linera, Raquel Gutiérrez Aguilar y Jaime Iturri Salmón, eds. La Paz: Punto Cero Editorial. 247-279.

---. 2003. "Quemar el archivo: un ensayo en contra de la Historia". Temas Sociales. Revista de Sociología - UMSA 24. 367-400.

---. 2004. De cuando en cuando Saturnina. Saturnina from time to time. Una historia oral del futuro. La Paz: Editorial Mama Huaco.

---. 2011. Descolonización. Crítica y problematización a partir del contexto boliviano. La Paz: ISEAT. 
STOLCKE, Verena. 2000. “¿Es el sexo para el género lo que la raza para la etnicidad... y la naturaleza para la sociedad?". Política y Cultura 14. 2560.

---. 2004. "La mujer es puro cuento: La cultura del género". Estudos Feministas 12 (2): 77-105.

VENTURA i OLLER, Montserrat. 2015. “Un pasado que no pasa: reflexiones amerindias". Quaderns-e de l'Institut Català d'Antropologia 20 (2): 5365.

WALLERSTEIN, Immanuel. 1987. "The Construction of Peoplehood: Racism, Nationalism, Ethnicity”. Sociological Forum 2 (2): 373-388.

WOLF, Erik R. 2005 [1982]. Europa y la gente sin historia. Agustín Barcenas, trad. México, D.F.: Fondo de Cultura Económica. 